\title{
Histopathology findings of the pelvic organ prolapse
}

\author{
FERNANDA M.A. CORPAS ${ }^{1}$, ANDRES ILLARRAMENDI ${ }^{2}$, \\ FERNANDA NOZAR ${ }^{3}$, BENEDICTA CASERTA $^{4}$
}

${ }^{1}$ Asistente Clínica Ginecotocológica A CHPR, ${ }^{2}$ Residente de Ginecología, Clínica Ginecotocológica A CHPR, ${ }^{3}$ Profesora Adjunta Clínica Ginecotocológica A CHPR, ${ }^{4}$ Jefa del servicio de Anatomía Patológica del CHPR, Presidenta de la Sociedad de Anatomía Patológica del Uruguay, Centro Hospitalario Pereira Rossell (Chpr),

Montevideo, Uruguay

Abstract: Pelvic organ prolapse is a benign condition, which is the result of a weakening of the different components that provide suspension to the pelvic floor. Surgical treatment, traditionally involve a vaginal hysterectomy, although over the last few decades the preservation of the uterus has become more popular. The objective of the paper is to analyze the characteristics of those patients diagnosed with pelvic organ prolapse, whose treatment involved a vaginal hysterectomy and its correlation to the histopathological characteristics. Retrospective, descriptive study. Data recovered from the medical history of patients that underwent surgical treatment for pelvic organ prolapse through vaginal hysterectomy, were analyzed in a 2 years period, in the CHPR, and compared to the pathology results of the uterus. At the level of the cervix, 58,2\% presented changes related to the prolapse (acantosis, para and hyperqueratosis) and 43,6\% chronic endocervicitis. Findings in the corpus of the uterus were $58,2 \%$ atrophy of the endometrium, $21 \%$ of endometrial polyps and $30.9 \%$ leiomiomas and 1 case of simple hyperplasia without cellular atypias. No malignant lesions were found. The pathology results of the uterus reveal the presence of anatomical changes related to the pelvic organ prolapse and in accordance to the age of the patient, as well as associated pathologies to a lesser extent. As we were able to establish, in most cases the removal of the uterus is not due to a pathology of the uterus itself but to a symptom generated by the failure of the suspension system of the pelvis.

Keywords: Genital prolapse; Pelvic Organ Prolapse; Hysterectomy; Conservative treatment; Histopathology

\section{INTRODUCTION}

Pelvic organ prolapse is a very common benign condition, unique to the human species, consequence of bipedastation. It is the result of a weakening of the different components that provide suspension to the pelvic floor, affecting the biosocial wellbeing of the woman.

The static of the female genital organs within the pelvis is the consequence between a balance including factors like bipedestation, intrabdominal pressure and structures that provide suspension to the abdominal- pelvic organs. The form and function of these organs is created by a synergy between ligaments, muscles and fascia.

This affliction does not present a clinical-anatomical correlation, that is to say, those symptoms generated by different defects may be very diverse among different patients, existing multiple forms of treatment. Knowing with precision each component of the affected anatomical structures allows to find the origin of the organ dysfuntion. The variation of symptoms and cascade of events may be secondary to the sum of small imbalances involving structures that maintain form and function. The severity of these symptoms do not correlate with the severity of the organ prolapse.

Many women are asymptomatic and do not need treatment. The incidence of symptomatic pelvic organ prolapse is approximately $15 \%$, although it is difficult to estimate due to the lack of methods to evaluate real symptoms and the lack of information regarding patients that in fact make a medical consultation for this matter ${ }^{1}$. It is expected that medical consultations due to symptoms regarding pelvic organ prolapse increase over the next few years due to an increase in life expectancy ${ }^{2}$, especially for women over the age of $65^{3}$, which means a longer life expectancy post corrective surgery and thus an increase in the possibility of treatment failure and long term complications ${ }^{2}$. This condition presents a recurrence rate in one third of treated patients.

Gynecological consults for problems related to genital prolapse are nowadays more frequent as are greater the expectations and demands in regards to treatment ${ }^{2}$.

There are a great variety of options when it comes to treatment, non surgical (pelvic floor muscle excercises, pessa- ries), and surgical ${ }^{4}$. The estimated risk with surgical interventions for prolapse is between $11-19 \% \%^{1,3,5,6}$, with a $29 \%$ risk of a second operation ${ }^{6}$.

Among those prolapsed compartments, the anterior compartment is the most common, three times more frequent than the posterior compartment and two times more than the apical compartment (uterus or vaginal dome). The pelvic organ prolapse is dynamic and in approximately two thirds of woman more than one compartment is involved ${ }^{1}$. The probability to develop a grade III or IV prolapse in the female population at some time in their lives is around 3 to $6 \%{ }^{2}$. The objective of correctional surgery for severe genital prolapse should be the relief of symptoms ${ }^{2,6}$, maintaining and eventually improving the functionality of the pelvic organs as well as the anatomical reestablishment ${ }^{2}$.

Vaginal hysterectomy, including some type of vaginal dome suspension has traditionally been the most common surgical treatment for prolapse of the uterus ${ }^{3,6,7,8}$, despite that the descent of the uterus is a consequence and not a cause of the prolapse $^{7}$, but the preservation of the uterus is a technique that is gaining more ground over time $\mathrm{e}^{1,6,8}$. Over the last few decades, there have been profound changes among women concerning their beliefs and perspectives towards their sexual and reproductive functionality and many women who undergo genital prolapse surgery wish to preserve their uterus ${ }^{7,8}$.

At the time of choosing a procedure, various factors should be taken into account such as age, presence of comorbidities, level of physical activity, the patients preference, as well as the surgical experience and preference of the gynecologist ${ }^{3}$. The objective of this paper is to analyze the clinical and social demographic characteristics of those patients diagnosed with pelvic organ prolapse, who underwent a vaginal hysterectomy and its correlation with the histopathological characteristics of the uterus.

\section{MATERIALS AND METHODS}

Descriptive retrospective study. Data taken from medical history charts of patients that underwent a vaginal hysterectomy as a surgical treatment for pelvic organ prolapse and not for pathogies of the uterus itself, between the period 
of March 12016 through March 12017 at the CHPR were analysed and compared to the pathology results of the uterus. The inclusion criteria were those patients who underwent a vaginal hysterectomy as the main treatment for an pelvic organ prolapse .

The variables analyzed among these patients were the age at the moment of consultation, the presence of comorbidities such as hypertension, diabetes, smoking, chronic respiratory disease, body mass index, parity, symptoms that motivated consultation and total grade of organ prolapse, analized by component.

\section{RESULTS}

55 cases were analyzed. Analysis of the different variables are represented in table 1.

The age range with greater incidence was that between 51 and 69 years $(36,4 \%)$, followed by 61 to 70 years $(30,9 \%)$. The forms of presentation were: genital tumor $(76,4 \%)$ and urinary symptoms $(50,9 \%) .58,2 \%$ of patients presented a grade III or IV hysterocele.

TABLE 1. Demographic characteristics and physical findings in patients.

\begin{tabular}{|c|c|c|c|}
\hline & & $\mathrm{N}(\%)$ & Middle \\
\hline \multirow{5}{*}{ Age } & $\leq 50$ years & $1(1.8)$ & 47 \\
\hline & $51-60$ years & $20(36.4)$ & 54,9 \\
\hline & $61-70$ years & $17(30.9)$ & 65,2 \\
\hline & $71-80$ years & $16(29.1)$ & 74,5 \\
\hline & $\geq 81$ years & $1(1.8)$ & 88 \\
\hline \multirow{5}{*}{$\begin{array}{l}\text { Parity - Vaginal } \\
\text { delivery }\end{array}$} & 0 & $2(3,6)$ & - \\
\hline & 1 & $5(9,1)$ & 1 \\
\hline & $2-4$ & $31(56,4)$ & 2,5 \\
\hline & $\geq 5$ & $14(25,4)$ & 6,6 \\
\hline & No data & $3(5,5)$ & - \\
\hline \multirow{4}{*}{ BMI } & $18.5-24,9$ & $3(5,5)$ & 23,2 \\
\hline & $25-29,9$ & $8(14,5)$ & 27 \\
\hline & $\geq 30$ & $6(10,9)$ & 36,3 \\
\hline & No data & $38(69,1)$ & $\sum$ \\
\hline \multirow{6}{*}{ Comorbidities } & Hypertensión arterial & $30(54,5)$ & - \\
\hline & Diabetes Mellitus & $8(14,5)$ & - \\
\hline & Smoker & $2(3,6)$ & - \\
\hline & Respiratory pathology & $3(5,5)$ & - \\
\hline & Dyslipidemia & $7(12,7)$ & - \\
\hline & No data & $4(7,3)$ & - \\
\hline \multirow{8}{*}{ Symptomatology } & Tumoration & $42(76,4)$ & - \\
\hline & IU effort & $4(7,3)$ & - \\
\hline & IU urgency & $8(14,5)$ & - \\
\hline & IU mixed & $14(25,5)$ & - \\
\hline & Incontinence gases & $2(3,6)$ & - \\
\hline & Incontinence matter & $1(1,8)$ & - \\
\hline & Other & $4(7,3)$ & - \\
\hline & No data & $5(9,1)$ & - \\
\hline \multirow{4}{*}{$\begin{array}{l}\text { Degree of total } \\
\text { genital prolapsed }\end{array}$} & II & $10(18,2)$ & - \\
\hline & III & $23(41,8)$ & - \\
\hline & IV & $17(30,9)$ & - \\
\hline & No data & $5(9,1)$ & - \\
\hline \multirow{4}{*}{$\begin{array}{l}\text { Degree of uteri- } \\
\text { ne prolapse }\end{array}$} & II & $8(14,5)$ & - \\
\hline & III & $16(29,1)$ & - \\
\hline & IV & $14(25,5)$ & - \\
\hline & No data & $14(25,5)$ & - \\
\hline
\end{tabular}

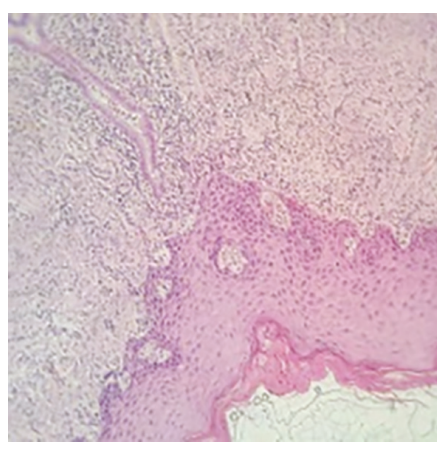

Figure 1. Cervical changes related to the prolapsed

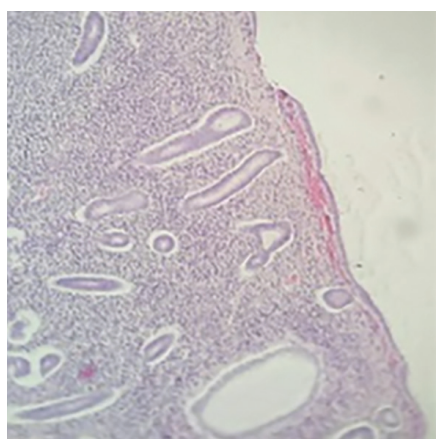

Figure 2. Atrophic endometrium

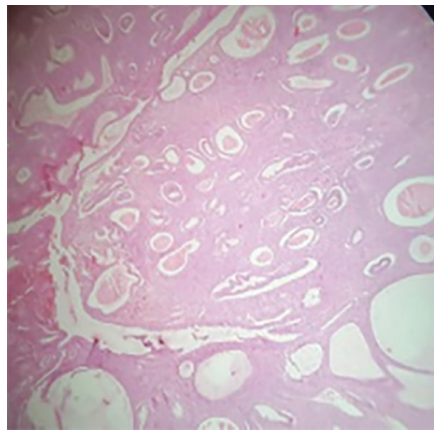

Figure 3. Endometrial polyps

In 50 cases only hysterectomy was performed, in 5 cases hysterectomy with annexectomy, in 2 cases of hysterectomy morcellation corresponding to multiple leiomiomas was performed.

The largest uterine dimension measure was in the range of 35 to $110 \mathrm{~mm}$. The weight in a range that went from 35 to 512 grs. Those greater than 100 grs ( 7 cases) presented endometrial polyps and/or leiomiomas in posterior studies. At the level of the cervix, 58,2\% presented changes related to the prolapse (acantosis, para and hypercheratosis, figure 1) and $43,6 \%$ chronic endocervicitis.

Findings in the uterine corpuses were in $58,2 \%$ atrophic endometrium (32 cases) figure 2, and 12 cases of endometrial polyps $(21 \%)$ figure 3 , in 17 cases $(30,9 \%)$ leiomiomas (4 cases associated to polyps) and 1 case of simple hyperplasia without cellular atypias. No malignant lesions were found in this series.

\section{DISCUSSION}

The concept that if the uterus is descended it's removal is necessary dates back to the year 1500 , considered the hysterectomy in combination with procedures as the primary 
procedure of the prolapsed uterus ${ }^{9}$

Nonetheless, the knowledge of the functional system of support of the pelvic organs, as well as the functional relevance of the uterus beyond its reproductive potential have put and still put to discussion the therapeutic indication of the hysterectomy as a resolution to a hysterocele.

From an anatomical functional point of view, the pericervical ring is a section where main structures come together not only for the suspension of the uterus, but also of the bladder, rectum and Douglas. With this in min, it is not difficult to imagine the anatomical consequences that a total hysterectomy generates. Thus, the premise of current female pelvic organ prolapse surgery is the preservation and maintenance of function, generating less morbidity. The error perhaps arises in an incorrect diagnostic interpretation of the true structures responsible for the hysterocele, being these the therapeutic objective and not the organ in which its flaw is expressed by.

We must highlight that underestimation of the uterus beyond its reproductive function is not exclusive to physicians, women also consider that a hysterectomy will not affect function or change the anatomical structure ${ }^{10}$.

Traditionally, the surgical treatment of patients with prolapse consisted in a vaginal hysterectomy with or without colposupension techniques. Nevertheless, women present with more frequency an increased desire to preserve their uterus for a variety of reasons.

Even in literature on the matter the effectiveness and effects of a hysterectomy for treatment of a prolapse is debated. Recent literature suggest that the preservation of the uterus is an appropriate option for certain women ${ }^{11}$ and many of them prefer this ${ }^{8}$.

The analysis of the physiopathology of genital prolapse proposes the question concerning what the best procedure for its correction is ${ }^{2}$. Although histerectomy is still considered a standard practice for the correction of prolapse, even though the descent of the uterus is a consequence and not a cause of it, over the last decades women's lifestyles, beliefs and perspectives in regard to sexual function and pregnancy have had profound changes and many patients that undergo surgery for the correction of genital prolapse choose to conserve their uterus ${ }^{7}$.

Multiple surgical procedures that conserve the uterus have been described for the correction of an apical prolapse such as: sacrohysteropexia, sacrospinal hysteropexia and procedures based on the use of vaginal surgical meshes, among others ${ }^{1,7,8}$. The technique may be vaginal, abdominal or laparoscopic ${ }^{1}$. Another conservative option is the Manchester Fothergill operation?

The conservation of the uterus is a safe alternative, feasable and effective for women that wish to preserve the uterus $^{5,6,12,13}$, associating similar results compared to a hysterectomy, both anatomical and functional ${ }^{4,12}$. Conservative techniques have less morbidity, duration and bleeding, also having the benefit to allow better therapeutic results in the three compartments of the pelvis as well as a smaller chance of recurrence $\mathrm{e}^{14,15,16,17}$. There are no differences in results regarding symptoms or concerning the patients satisfaction with the treatment for a prolapsed uterus ${ }^{6}$.

Multiple reasons may be identified in favor of the preservation of the uterus such as: avoiding early and late onset complications of the hysterectomy ${ }^{1,3,4,6}$, decreasing the rate of erosion of the mesh if used at the time of the hysterec- tomy ${ }^{1}$, reducing the cost of the surgery due to a shorter surgery, as well as shorter hospital stay ${ }^{1,3,4,6,13}$ and also avoiding the risk of prolapse of the vaginal dome ${ }^{1}$. Other reasons are the patients desire to preserve the uterus, either to preserve parity, maintain a personal identity, or cultural and religious considerations ${ }^{1}$. The preservation of the uterus contributes positively to the patients self esteem, body image, confidence and sexuality ${ }^{1}$.

The Manchester Fothergill Procedure is a good method for uterine preservation, but it elevates the recurrence rate of the prolapse, especially if it is a high grade ${ }^{1,5}$. It also associates cervical stenosis and its complications such as hematometra and difficulties for the diagnosis of endometrial patho$\operatorname{logies}^{1,6}$.

As a result of the our society's shift in attitud in respect to sexuality and the pychological and emotional value of the sexual organs, is that we should take into consideration the patients wishes to preserve vaginal and uterine functions ${ }^{4}$. An adequate counseling and preoperative evaluation prior to the procedure should be provided ${ }^{4}$.

It is difficult to provide recommendations in this sense due to the fact that there are few high quality studies available. It is in this point in particular that we should take into account that when it comes to surgery it is impossible for class A studies to have not an infinity of confusing variables. Due to current knowledge as well as the need to create surgeries with less morbidity is that we consider that uterine preservation should be a valid option in prolapse surgery.

The risk of not identifying a malignant pathology in the uterus, be it cervical and/or endometrial in patients with a uterine prolapse is low if an adequate preoperative assessment is performed. Even if a hysterectomy or cervical amputation are performed it is recommended that those pieces be sent for pathology study ${ }^{18}$.

\section{CONCLUSIONS}

The anatomical pathology study of the uterus reveals the presence of anatomical changes related to the pathology and to the age of the patient, as well as associated pathologies to a lesser extent. Although the risk of unidentifying a malignant pathology of the uterus is low, the anatomical- pathology of the surgical piece is recommended.

As we have seen the removal of the uterus in most cases is performed not for the pathology itself but as a symptom of a failure in the suspension system.

\section{REFERENCES}

1. Fink K, Shachar IB, Marcus N Uterine preservation for advanced pelvic organ prolapse repair: Anatomical results ad patient satisfaction. Int braz J Urol. 2016; 42: 773-8

2. Braun HB, Rojas IT, Gonzalez F et al. Prolapso genital severo: consideraciones clinicas, fisiopatologicas, y de tecnica quirurgica al momento de su corrección. Rev Chil Obstet Ginecol 2004; 69 (2): 149-156

3. Detollenaere RJ, den Boon J, Vierhout M et al. Uterussparende chirurgie versus vaginale hysterectomie als behandeling van descensus uteri. Ned Tijdschr Geneeskd. 2011;155:A3623

4. Kow N, Goldman HB, Ridgeway B Management Options for Women with Uterine Prolapse Interested in Uterine Preservation. Current Urology Reports. 2013; 14 (5): 395-402.

5. Marschalek J, Trofaier ML, Yerlikya G et al. Anatomic outcomes after pelvic-organ - prolapse surgery - comparing uterine preservation with hysterectomy. European Journal of Obstetrics \& Gynecology and Reproductive Biology, 2014; 183: 33-36. 
6. Bergman I, Soderberg MW, Kjaeldgaard A, Ek M Cervical amputation versus vaginal hysterectomy: a population-based register study. Int Urogynecol J 2017; 28: 257-266

7. Costantini E, Mearini L, Bini V et al. Uterus Preservation in Surgical Correction of Urogenital Prolapse. European Urology 2005; 48: 642-649

8. Korbly NB, Kassis NC, Good MM, et al. Patient preferences for uterine preservation and hysterectomy in women with pelvic organ prolapse. Am J Obstet Gynecol 2013; 209: 470.e1-6.

9. Swati JHA, Moran PA. National survey of prolapse in the UK Neurol Urodyn 2007; 26: 325-331

10. Good MM, Korbly N, Kassis NC, et al. Prolapse-related knowledge and attitudes toward the uterus in women with pelvic organ prolapse symptoms. Am J Obstet Gynecol 2013; 209:481. e1-6

11. Diwan A, Rardin CR, Kohli N. Uterine preservation during surgery for uterovaginal prolapse: a review. Int Urogynecol J Pelvic Floor Dysfunct, 2004; 15(4): 286-92

12. Li-Yi Huang, Li-Ching Chu, Hsin-ju Chiang, Fei-chi Chuang, Fu-Tsai Kung, Kuan-Hui Huang. Medium-term comparison of uterus preservation versus hysterectomy in pelvic organ prolapsed treatment with Prolift ${ }^{\mathrm{TM}}$ mesh. International Urogynecology Journal, 2015; 26 (7): 1013-1020

13. Zucchi A, Lazzeri M, Porena $M$ et al. Uterus preservation in pelvic organ prolapse surgery. Nature Reviews Urology 2010; 7: 626-633

14. Maher CF, Cary MP, Slack CJ, Murray CJ, Milligan M, Schluter P. Uterine preservation or hy terectomy at sacrospinous colpopexy for uterovaginal prolapse. Int Urogynecol J 2001; 12 : $381-385$
15. Brummen HJ, van de Pol G, Aalders CIM, Heintz APM, van der Vaart CH. Sacrospinous hysteropexy compared to vaginal hysterectomy as primary surgical treatment for a descensus uteri: effects on urinary symptoms. Int Urogynecol J 2003; 14: 350-355

16. Dietz V, Schraffordt Koops S, Van Der Vaart H. Vaginal surgery for uterine descent; which options do we have? A review of the literature. Int Urogynecol J 2009; 20: 349-356

17. Farthmann J, Watermann D, Erbes T, Roth K, Nanovska P, Gitsch G, Gabriel B. Functional outcome after pelvic floor reconstructive surgery with or without concomitant hysterctomy. Arch Gynecol Obstet 2015; 291:573-577

18. Wan OY, Cheung RY, Chan SS, Chung TK. Risk of malignancy in women who underwent hysterectomy for uterine prolapse. Aust N Z J Obstet Gynaecol. 2013; 53(2): 190-6 characteristics of the uterus.

\section{Disclosure Statements}

There was no conflict of interest and the authors of the publication did not receive any financial support by any grant/research sponsor.

\section{Correspondence to:}

Andres Illarramendi - gregorio suarez 2723/901

Montevideo 11100 MO - Uruguay

E-mail: fernandanozar@gmail.com 